\title{
Estimation of Sedimentation Rate of a Reservoir using Remote Sensing Data: a case study of Tehri Reservoir
}

\author{
Shivangi Tiwari ${ }^{1}$, Sameer Verma ${ }^{2}$ and Surajit Ghosh ${ }^{3}$
}

\begin{abstract}
The most commonly encountered problem in a reservoir is the loss of its storage capacity due to sedimentation, which if exceeds a certain level consequently leads to shortening of the life of the dam associated with the reservoir. Various methods and models are used for the assessment, analysis as well as prediction of reservoir sedimentation. Remote sensing being an effective and time saving method is used in the present paper, to assess the reservoir sedimentation in Tehri reservoir, Uttarakhand, India. Due to sedimentation in the reservoir, the elevation (stage) changes with time and with it the water spread area of a reservoir also changes. An adaptive technique was applied for extracting of water-spread area of the reservoir at any particular elevation by using multi dated satellite imageries (LANDSAT5 TM) and SRTM DEM. This facilitates to estimate sedimentation over a period of time. The revised capacity of the reservoir between maximum and minimum levels was computed using the trapezoidal formula. The loss in reservoir capacity in water elevation fluctuation zones due to deposition of sediments for a period of 5 years (2006-2011) was determined to be $62.62 \mathrm{Mm} 3$, which gives an average sedimentation rate of $12.52 \mathrm{Mm} 3$ year-1 in the Tehri reservoir.
\end{abstract}

Keywords - Tehri reservoir, storage capacity, sedimentation, remote sensing.

\section{INTRODUCTION}

The reservoirs are built on rivers that feed them with water but also carry certain amount of sediment load which is carried in suspension as turbid water. These sediments settle down in the vicinity of the dam where the velocity and turbulence are considerably reduced. This deposition of sediment in the reservoir is known as Reservoir Silting or Reservoir Sedimentation. This

\footnotetext{
1 Department of Civil Engineering THDC Institute of Hydropower Engineering and Technology, Tehri, Uttarakhand, India

2 Department of Civil Engineering THDC Institute of Hydropower Engineering and Technology, Tehri, Uttarakhand, India
}

${ }^{3}$ Indian Institute of Remote Sensing, Dehradun, Uttarakhand, India 
sedimentation is detrimental for the life of the reservoir. The entire Himalayan region is afflicted with a serious problem of soil erosion and therefore the rivers flowing through this region transport a heavy load of sediment. The silt transported by the rivers and their tributaries is deposited in the reservoirs reducing the capacity of the reservoirs and affecting their useful life. Sediment deposition into reservoirs built for hydropower generation has several major detrimental effects which include loss of storage capacity, damage to or impairment of hydro equipment and effect on water quality.

Assessment of reservoir sedimentation help in ensuring remedial measures is taken well in advance so that the reservoir operation schedules can be planned for optimum utilization. For this assessment the two most common conventional techniques for quantifying sedimentation in a reservoir are (a) Direct measurement of sediment deposition by hydrographic surveys (b) Indirect measurement using the inflow-outflow records of a reservoir. Both of these methods are cumbersome, time overwhelming and expensive. Remote sensing techniques which are effective, easy to use and requires less time, offering data acquisition over a long time period and for a broad spectral range, are considered superior to the conventional methods for data acquisition. Remote sensing data provides invaluable synoptic information regarding (a) changes in the water-spread area of the reservoir after deposition of sedimentation and (b) sediment distribution patterns in the reservoir.The present study deals with an assessment of sedimentation in Tehri reservoir located on the Bhagirathi River, Uttarakhand using remotely sensed data.

\section{Algorithm}

\section{A. Study Site-}

The Tehri dam, at a height of $640 \mathrm{~m}$ from Mean Sea Level, is situated in the Himalayas and is fed by the Bhagirathi river (originating from the Gangotri glacier) and its tributary Bhilangana (origin, Khatling glacier) [1] which is mainly the contribution of rain and snowmelt (Fig 1). The dam is a $260.5 \mathrm{~m}$ clay core Earth \& Rockfill dam across the Bhagirathi River and is one of the highest dams of its type in the world. The dam was commissioned during 2006-2007. The Tehri Reservoir has a designed dead storage of $925 \mathrm{Mm}^{3}$ and live storage of 2615 $\mathrm{Mm}^{3}$ i.e. a total storage capacity of 3540 $\mathrm{Mm}^{3}$. The water-spread area of the Tehri Reservoir extends over $42 \mathrm{~km}^{2}$ at full reservoir level $(830 \mathrm{~m})$. (Report on impact of tehri dam lessons learnt, 2008).

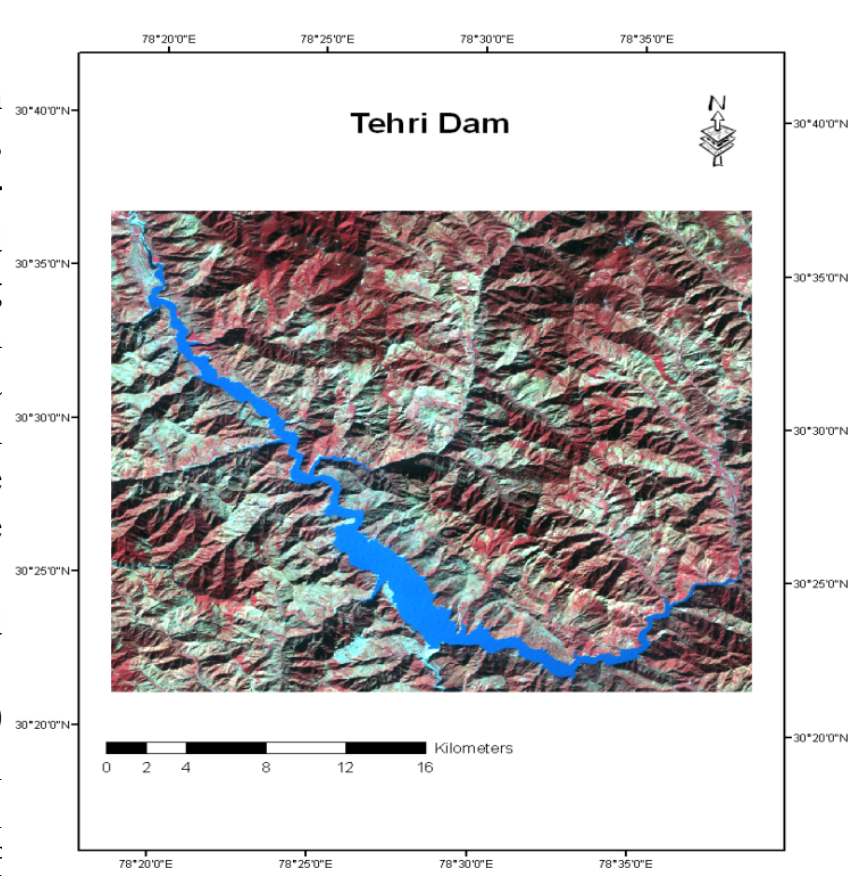

Figure 1. Tehri Reservoir

\section{B. Data-}

The LANDSAT5 satellite data (Thematic Mapper sensor, spatial resolution of $30 \mathrm{~m}$ ) were 
obtained from the United States Geological Survey, USA. These were digital multi spectral data of seven bands (0.45-0.52 blue, 0.52-0.60 green, 0.63-0.69 red, 0.77-0.90 NIR, 1.55-1.75 SWIR, 10.40-12.50 thermal, 2.09-2.35 SWIR) which of them, three are visible bands, one is nearinfrared band two are short wave infrared bands and one is thermal band. After browsing the data of the study area, seven cloud-free dates (26 September 2010, 28 October 2010, 29 November 2010, 15 December 2010, 01 February 2011, 22 April 2011 and 08 May 2011) were identified and used in the present study. Each scene of data consisted of six bands, leaving the thermal band.

The Shuttle Radar Topography Mission (SRTM) on its 11-day mission in February of 2000 obtained digital topographic maps of Earth called Digital Elevation Model (DEM). SRTM DEM with $90 \mathrm{~m}$ spatial resolution, which is freely available, is used for this study.

\section{Methodology-}

The method adopted for the reservoir study was processing of available cloud free satellite image, identifying and extracting the pure water pixels and working out the capacity thereof and comparing this data with the data derived from SRTM DEM of the reservoir area. SRTM DEM (90m resolution) was resampled into $30 \mathrm{~m}$ for its comparative study with the $30 \mathrm{~m}$ resolution LANDSAT 5 data. The method is discussed in brief below.

Firstly, LANDSAT5 TM geometrically corrected images were converted from DN (digital number)values into the radiance and then to Top of Atmosphere (TOA) reflectance images. Using the Equation 1, applicable for all bands of LANDSAT, radiance images are generated.

$$
L=((\operatorname{Lmax}-L \min ) / 255) *(D N)+L \min
$$

-Equation 1

Where $\mathrm{L}$ is radiance $(\mathrm{Watt} /(\mathrm{m} 2 * \mu \mathrm{m} / \mathrm{ster})), \mathrm{DN}$ is pixel values of landsat data. The values of Lmax and Lmin are obtainable from the data of the satellite image. The radiance image obtained as above is converted to reflectance image using Equation 2, reflectance image helps in better comparison among different scenes by eliminating the differences caused by sun position and energy output by sun in different bands.

TOA $=(L *(22 / 7) * d 2) /(E 0 * \cos (90-$ sun elevation angle $))$

-Equation 2

Where, 'TOA' is the top of atmosphere reflectance (a unit less ratio), 'L' (Watt/ $(\mathrm{m} 2 * \mu \mathrm{m} / \mathrm{ster})$ ) is the band radiance calculated from equation 1, ' $\mathrm{d}$ ' is Earth -Sun distance in astronomical unit. The value of ' $d$ ' and Sun elevation angle (obtained from meta data of the satellite image) depend on the time when image was captured. 'E0' [Watts/ $(\mathrm{m} 2 * \mu \mathrm{m})$ ] is the Mean solar exo-atmospheric irradiance for given wavelength in [2], shown in Table 1.

Table-1 $\mathrm{E}_{0}$ for LANDSAT 5 TM.

\begin{tabular}{|l|l|l|l|l|l|l|}
\hline Band & 1 & 2 & 3 & 4 & 5 & 6 \\
\hline $\begin{array}{l}\mathrm{E}_{0}[\text { Watts/ } \\
\left.\left(\mathrm{m}^{2} * \mu \mathrm{m}\right)\right]\end{array}$ & 195.7 & 182.9 & 155.7 & 104.7 & 21.93 & 7.452 \\
\hline
\end{tabular}


For the estimation of sedimentation rate in the reservoir, the basic information that needs to be extracted from the reflectance image of the cloud free satellite data is the water-spread area of the reservoir at different water elevations. The pixels representing water-spread area of the reservoir were clearly identified by adopting threshold (Th) determination technique using the decision tree approach to find out the pure water pixels by analyzing histogram of Band 5. The histograms showed two peaks between water and other objects and smooth dip between the peaks. Band 5 was chosen because the spectral value of water is less compared to other features in Band 5, i.e. spectral reflectance of water is least in this band, easy to detect water bodies[3]. The value near the crest of other objects was adopted as threshold. Overlapping with the original image; it was found that practically all the water pixels are extracted, however some shadow pixels may also be obtained, which can be removed by observing spectral responding curves in Band 2 (green) which show higher spectral value for water than that of shadow pixels[4]. This in most cases lead to exact answer, however in case of turbidity in water some water pixels were lost. To recover lost water pixels spectral curves for other bands were drawn and led to following decision tree (Fig 2). The spectral values for different bands are mentioned in the table following the decision tree. Threshold values for band 3 and band 4 are made use of only in case of slight foggy atmosphere or when the water is turbid, as here for May 08, 2011 image.

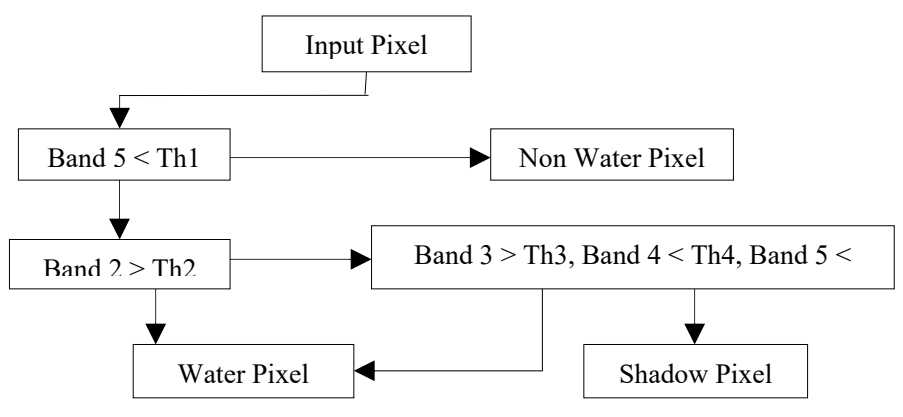

Figure. 2. Decision tree for water pixel determination

Table-2 Threshold values for various bands. 


\begin{tabular}{|l|l|l|l|l|l|}
\hline Date & $\begin{array}{l}\text { Band 2 } \\
(\text { Th2 })\end{array}$ & $\begin{array}{l}\text { Band3 } \\
(\text { Th3 })\end{array}$ & Band4 (Th4) & Band5 (Th1) & $\begin{array}{l}\text { Band5 } \\
\text { Th5) }\end{array}$ \\
\hline 26-SEP-2010 & $>0.87$ & & & $<0.417$ & \\
\hline $\begin{array}{l}28-O C T- \\
2010\end{array}$ & $>0.54$ & & & $<0.2$ & \\
\hline 29NOV-2010 & $>0.66$ & & & $<0.236$ & \\
\hline $\begin{array}{l}15-\text { DEC- } \\
\text { 2010 }\end{array}$ & $>1.043$ & & & $<0.44$ & \\
\hline 01 -FEB-2011 & $>1.2$ & & & $<0.288$ & \\
\hline $\begin{array}{l}\text { 22-APR- } \\
\text { 2011 }\end{array}$ & $>0.67$ & & & $<0.421$ & \\
\hline $\begin{array}{l}08-\text { MAY- } \\
\text { 2011 }\end{array}$ & $>0.69$ & $>0.4$ & $<0.655$ & $<0.442$ & $<0.5$ \\
\hline
\end{tabular}

SRTM DEM was used to find out the water inundation area which was compared with satellite imagery toknow water elevation of the study dates. From DEM, the original areas at the reservoir elevations and the volume on the dates of satellite pass were estimated, as there is no evidence of any tectonic activity in the region during the year DEM was obtained (2002) till the commissioning of the dam (2006), the DEM provides the original data correctly(Table 3).

The widely used trapezoidal formula [5] has been employed here for computation of reservoir capacity between two consecutive reservoir elevations. This method applies a conic geometry to each stage increment to approximate the non linear relationship between stage and water surface area. Differences in elevations, together with surface areas at those elevations, were used to compute the sediment volumes for the revised data, as given

$$
V=H / 3 *\left(A_{1}+A_{2}+\sqrt{ }\left(A_{1} * A_{2}\right)\right)
$$

Where, $\mathrm{V}$ is the volume of water between two consecutive elevations,

$\mathrm{A}_{1}$ is the water spread area at elevation 1,

$\mathrm{A}_{2}$ is the water spread area at elevation 2 and

$\mathrm{H}$ is the difference between elevations 1 and 2 .

With these values of DEM derived and revised areas at different elevations, the corresponding original and revised capacities were determined. The cumulative values of the capacity for the two sets of data were calculated, taking capacity corresponding to minimum water level as the initial water volume of the reservoir. The volume of sedimentation deposited between the fluctuating reservoir levels is computed from the difference between cumulative original capacity and satellite-derived cumulative volume. 
Entimntion of Cadimantation Dota of a Recervoir ucino Remote Sencino Data• a cace studv of Tehri Reservoir 7.50
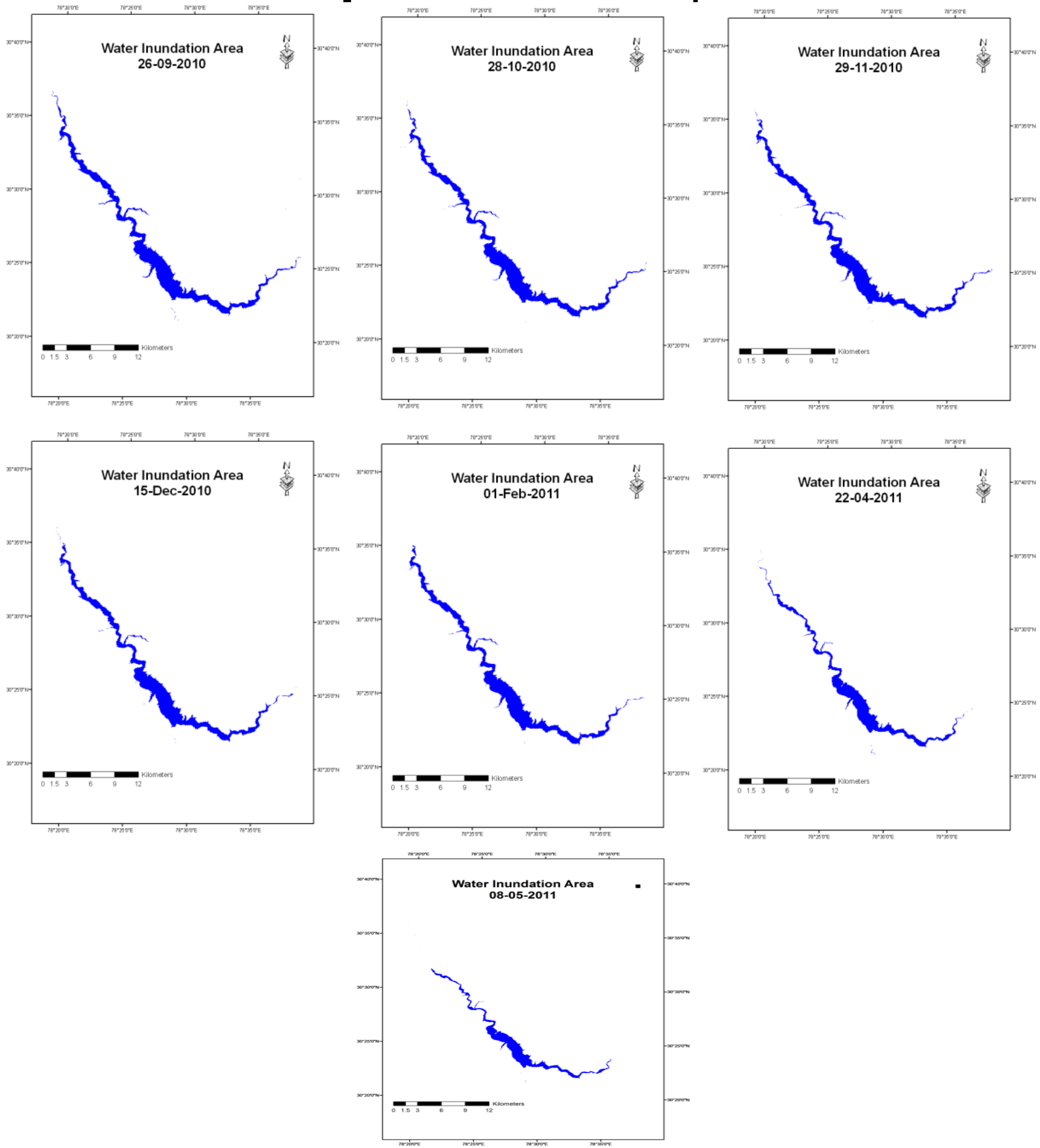

Figure 3. Water inundation images obtained by SWIR technique 


\section{EXPERIMENT AND RESULT}

The corresponding water-spread area of the reservoir was calculated using remotely sensed data for the elevations. The difference in volume between two consecutive levels was calculated using the trapezoidal formula and is given in Table 3. In the present study, the cumulative revised capacity of the reservoir at the observed lowest level (763 m on 08 May 2011) was assumed to be the same as the original cumulative capacity $\left(1296.89 \mathrm{Mm}^{3}\right)$ at this elevation. Above the lowest water level, the cumulative capacities between the consecutive levels were added up to arrive at the cumulative GIS derived and revised capacities at the maximum calculated level (823m on 26 September 2010). The difference between the GIS derived and estimated cumulative capacity represented the loss of the storage capacity of live zone of the reservoir due to the sediment deposition[6].

Table -3 Assessment of sediment deposition in Tehri Reservoir using remote sensing (RS) for the year (2010/2011)

\begin{tabular}{|c|c|c|c|c|c|c|c|}
\hline $\begin{array}{c}\text { Date of } \\
\text { satellite } \\
\text { pass }\end{array}$ & $\begin{array}{c}\text { Dem } \\
\text { derived } \\
\text { area } \\
\left(\mathrm{Mm}^{2}\right)\end{array}$ & $\begin{array}{l}\text { Reservoir } \\
\text { elevation } \\
\text { (m) }\end{array}$ & $\begin{array}{c}\text { Dem } \\
\text { derived } \\
\text { volume } \\
\left(\mathrm{Mm}^{3}\right)\end{array}$ & $\begin{array}{c}\text { Dem } \\
\text { derived } \\
\text { cumulative } \\
\text { volume } \\
\left(\mathrm{Mm}^{3}\right)\end{array}$ & $\begin{array}{c}\text { Revised } \\
\text { area } \\
\text { using } \\
\text { multi } \\
\text { temporal } \\
\text { data } \\
\left(\mathrm{Mm}^{2}\right)\end{array}$ & $\begin{array}{c}\text { Revised } \\
\text { volume } \\
\text { using } \\
\text { multi } \\
\text { temporal } \\
\text { data } \\
\left(\mathrm{Mm}^{3}\right)\end{array}$ & $\begin{array}{c}\text { Revised } \\
\text { cumulative } \\
\text { volume } \\
\text { using } \\
\text { multi } \\
\text { temporal } \\
\text { data } \\
\left(\mathrm{Mm}^{3}\right)\end{array}$ \\
\hline $\begin{array}{c}\text { 8-May- } \\
11\end{array}$ & 22.05 & 763 & & 1296.90 & 20.65 & & 1296.89 \\
\hline $\begin{array}{c}\text { 22-Apr- } \\
11\end{array}$ & 23.94 & 771 & 183.87 & 1480.77 & 23.42 & 176.17 & 1473.06 \\
\hline 1-Feb-11 & 34.22 & 807 & 1041.34 & 2522.12 & 33.47 & 1018.68 & 2491.74 \\
\hline $\begin{array}{c}\text { 15-Dec- } \\
10\end{array}$ & 35.98 & 812 & 175.49 & 2697.60 & 33.80 & 168.19 & 2659.93 \\
\hline $\begin{array}{c}\text { 29-Nov- } \\
10\end{array}$ & 36.33 & 813 & 36.16 & 2733.75 & 33.99 & 33.90 & 2693.83 \\
\hline $\begin{array}{c}28-O c t- \\
10\end{array}$ & 37.19 & 815 & 73.52 & 2807.27 & 35.31 & 69.30 & 2763.12 \\
\hline \multirow[t]{2}{*}{$\begin{array}{c}\text { 26-Sep- } \\
10\end{array}$} & 40.11 & 823 & 309.12 & 3116.39 & 37.36 & 290.645 & 3053.77 \\
\hline & & & & & & & 12.52 \\
\hline
\end{tabular}

The capacity for the year 2010/11, estimated using remote sensing techniques $\left(3053.77 \mathrm{Mm}^{3}\right)$ was subtracted from the DEM derived capacity $\left(3116.39 \mathrm{Mm}^{3}\right)$ at the same level. The loss in capacity $\left(62.62 \mathrm{Mm}^{3}\right)$ was attributed to the sediment deposition in the zone of study, i.e. between $823 \mathrm{~m}$ and $763 \mathrm{~m}$ of the reservoir (Fig 3). This is the sedimentation in the dam during 5years (2006-2011). Thus, the average rate of loss of capacity is computed to be $12.52 \mathrm{Mm}^{3}$ year ${ }^{-1}$ for the live zone, which is the zone of water fluctuation in a reservoir, using remote sensing data. 


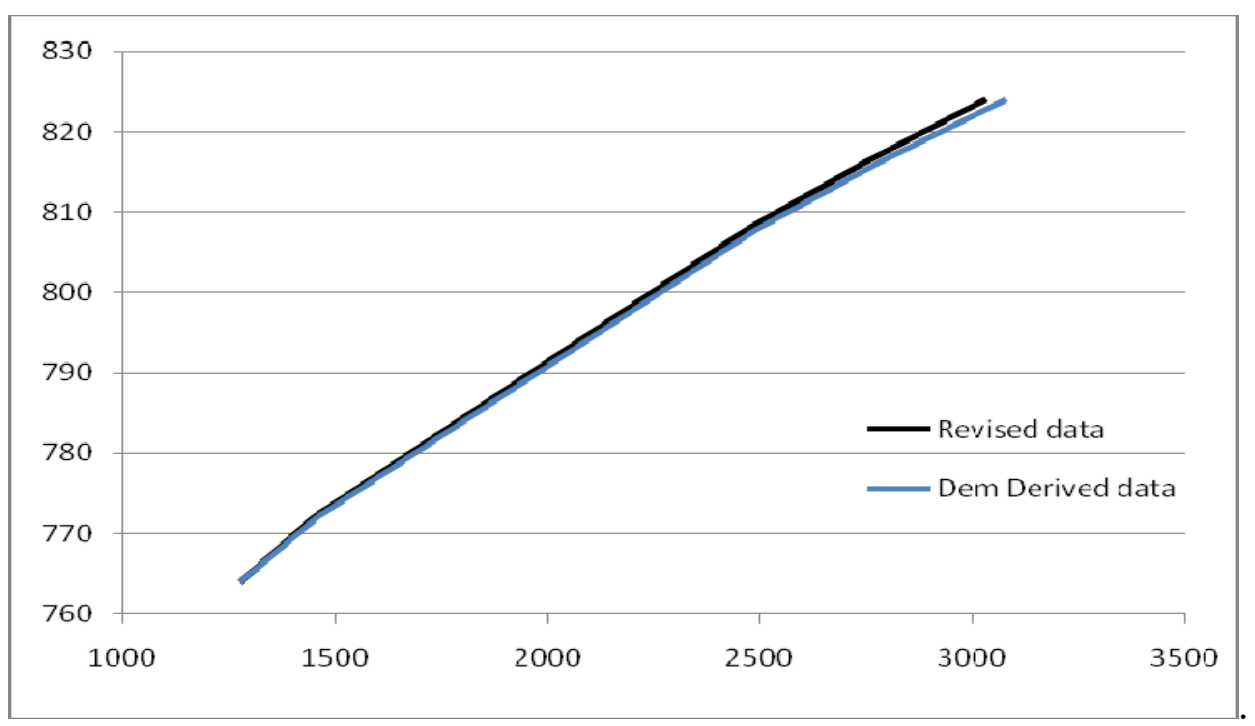

Figure 4. Elevation capacity curves for DEM derived and revised volumes of Tehri Reservoir $(2010 / 11)$

The Bhagirathi River transports heavy amounts of sediment, which is detrimental to the life of the reservoir. Besides the manmade causes, natural factors also attribute to high levels of sediment transportfrom the upstream are steep topographic gradient, poor structural characteristics of soils; the existence of limestone, quartzite and slate deposits[7]. [8] have studied precipitation distribution for several Himalayan basins and found that the maximum contribution to annual rainfall $(42-60 \%)$ is received during the monsoon season, whereas the minimum $(5-10 \%)$ is received in the post-monsoon season. Consequently, the reservoir attains its maximum water level just after the monsoon season. The water level of the reservoir gradually reduces due to various types of use and reaches lower levels before the onset of the next monsoon.

Table-4 Error in readings

\begin{tabular}{|c|c|c|c|}
\hline Date & $\begin{array}{c}\text { Reservoir elevation as } \\
\text { obtained from } \\
\text { THDCIL. }(\mathrm{m})\end{array}$ & $\begin{array}{c}\text { Reservoir elevation as } \\
\text { observed by Remote } \\
\text { Sensing. }(\mathrm{m})\end{array}$ & $\begin{array}{c}\text { Error in between two } \\
\text { observations. }(\mathrm{m})\end{array}$ \\
\hline 26-SEP-2010 & 825.80 & 823 & 2.80 \\
\hline 28-OCT-2010 & 819.95 & 815 & 4.95 \\
\hline 29NOV-2010 & 818.75 & 813 & 5.75 \\
\hline 15-DEC-2010 & 816.80 & 812 & 4.80 \\
\hline 01-FEB-2011 & 804.20 & 807 & -2.80 \\
\hline 22-APR-2011 & 778.75 & 771 & 7.75 \\
\hline 08-MAY-2011 & 764.35 & 763 & 1.35 \\
\hline
\end{tabular}




\section{IV.CONCLUSION}

The application of remote sensing techniques for estimating the sedimentation rate in the Tehri Reservoir, built on Bhagirathi River in the Himalayas in the state of Uttarakhand, led to the result that the average sedimentation rate for 5 years (2006-2011)(from the date of commissioning of the dam, 2006 till the date of study, 2011) is $11.02 \mathrm{Mm}^{3} \mathrm{year}^{-1}$. However, there are some limitations in the estimation of results by remote sensing method [9]. In this study, remote sensing techniques give the information on the capacities only in the water elevation fluctuation zone, which generally lies in the live zone of the reservoir, and hence the sedimentation gradient in live zone can only be calculated. Below this, in the dead load zone, the information on the capacity reduction due to sedimentation could be taken from the hydrographic survey conducted at the dam site, as the scope of estimation of sedimentation using satellite imagery is restricted only to water fluctuation zones. This method is widely accepted for reservoir sedimentation rate, so the result of the study is also accepted.

\section{REFERENCES}

[1] Bagchi D.\& Singh R.P.,Government of India, Ministry of Water Resources and Central Ground WaterBoard. Ground Water Brochure, District Tehri Garhwal, Uttarakhand (2011).

[2] Markham,B.L \& Barker J L. Landsat MSS and TM postcalibration dynamic ranges, exoatmospheric reflectances and at-satellite temperatures. EOSAT Tech. Notes 1, 3-8. Earth Obs. Satell. Co. Lanham, Maryland. 1986.

[3] Dube A.K. Cost and time over run in the construction of Tehri dam project.

[4] DU Jin-Kang, FENG Xue-zhi, WANG Zhou-long, HUANG Yong-sheng and RAMADAN Elnazir. The methods of extracting water information from SPOT image. Chinese Geographical Science, vol. 12, page 68-72. (2002).

[5] Govardhan V.(1993).Environment Impact Assessment of Tehri dam.

[6] Impact of Tehri dam lessons learnt, Water for welfare Secretariat, IIT Roorkee.2008

[7] Jain, S. K., Singh P. \& Seth S. M. (2002). Assessment of sedimentation in Bhakra reservoir in the Western Himalayan region using remotely sensed data. Hydrological SciencesJournal-des Science Hydrologiques. 47(2).

[8] Narasayya Kamuju, Narasaiah S., \& Roman U. C. Assessment of reservoir sedimentation using remote sensing satellite imageries.

[9] George Joseph. Basics of remote sensing.

[10] www.thdc.co.in (figure 1). 